\title{
Uso de ozônio no controle de fungos em sala de maturação de queijos
}

\author{
Moulds control by ozonization in ripening cheese room \\ Andrea Troller Pinto ${ }^{1}$, Verônica Schmidt ${ }^{1}$, Suely Aparecida Raimundo ${ }^{2}$ \& Fábio Raihmer ${ }^{2}$
}

\begin{abstract}
RESUMO
Os fungos fazem parte da microbiota normal das câmaras de maturação de queijos e, neste ambiente, podem tornarse indesejáveis por provocar alterações sensoriais, desclassificação dos produtos e defeitos, levando a perdas econômicas. Avaliou-se a eficiência do gás ozônio aplicado ao ar em câmara de maturação de queijos parmesão tipo Grana no controle de fungos em suspensão, na superfície de prateleiras e queijos em maturação. Foram realizadas três coletas, em intervalos regulares de vinte dias, de amostras de ar por sedimentação natural e de suabes de superfícies de prateleiras e queijos. Determinou-se, por contagem em ágar batata dextrose, o número de UFC de fungos ambientais antes e após a aplicação de ozônio no ar. Os suabes foram inoculados e diluídos em água peptonada $0,1 \%$ e semeados em agar dextrose batata para contagem das UFC/ $100 \mathrm{~cm}^{2}$. O ozônio mostrou-se efetivo no controle de fungos ambientais e superfícies, durante o processo de maturação dos queijos. Ao final do período, observou-se redução significativa da carga fúngica em $0,74 \log _{10}$ na superfície dos queijos, $0,91 \log _{10}$ na superfície das prateleiras e de $1,5 \log _{10}$ no ar.
\end{abstract}

Descritores: ozônio, fungos ambientais, maturação de queijo.

\begin{abstract}
Fungi are microorganisms of the ordinary microbiota in cheese ripening chambers. In this environment fungi may become undesired microorganisms due to the organoleptic changes they cause, lowering product quality and leading to economic losses. This study assessed the efficiency of gaseous ozone fumigation in a maturation chamber of parmesan cheese type Grana to control fungi suspended in the air as well as present on maturation shelves and on cheese undergoing maturation. Three sample collections were carried out at regular 20-day intervals. Samples consisted of spontaneous air sedimentation material as well as cheese and shelf surface swabs. The number of fungal CFU before and after ozone treatment was determined by potato dextrose agar counts. Swabs were inoculated and diluted in peptone water $0.1 \%$, and then seeded onto potato dextrose agar to establish $\mathrm{CFU} / 100 \mathrm{~cm}^{2}$. Ozone proved its effectiveness in controlling environment and surface fungi during the cheese ripening process. After sixty days, a significant decrease in fungal load was observed to be $0.74 \log _{10}$ on cheese surface, 0.91 $\log _{10}$ on shelf surface, and $1.5 \log _{10}$ in the air.
\end{abstract}

Key words: ozone, environmental molds, cheese ripening. 


\section{INTRODUÇÃO}

A presença de fungos ambientais é indesejável em câmaras de maturação de queijos. Algumas espécies são produtoras de micotoxinas, logo representam riscos à saúde [2,6,10]. A esterigmatocistina é a toxina mais encontrada em queijos [7,15].

As propriedades sensoriais podem ser alteradas pela produção de exoenzimas durante a multiplicação fúngica [2], provocando sabores estranhos [10] ou defeitos de coloração na superfície [5]. A presença de fungos em queijos duros no Brasil já foi investigada, com o isolamento de espécies micotoxigênicas [13], mesmo quando é utilizado ácido sórbico como conservante [8].

O ambiente das câmaras de maturação de queijos favorece a multiplicação fúngica devido às condições de temperatura e umidade. Ozônio pode ser aplicado de diversas formas na indústria de alimentos, inclusive na redução de carga fúngica ambiental [9]. Seu uso em câmaras de maturação de queijos reduz a quantidade de fungos em suspensão, entretanto não afetou os presentes nas superfícies de prateleiras, quando as mesmas não são higienizadas [11].

Seu uso é controverso devido a sua toxicidade e possíveis efeitos em alimentos. Dosagens baixas de ozônio (0,2 a 0,3 ppm) são capazes de prevenir o surgimento de fungos em queijos cheddar sem alterar suas características sensoriais [3]. Dosagens de até $10 \mathrm{mg} / \mathrm{m}^{3}$ de ozônio é capaz de inativar até $90 \%$ de propágulos fúngicos, sem provocar alterações sensoriais no produto [12].

O objetivo deste trabalho foi comprovar que a aplicação de ozônio em câmara de maturação de queijos pode ser útil no nível industrial para controlar a multiplicação de fungos no ar e nas superfícies de queijos e de prateleiras.

\section{MATERIAIS E MÉTODOS}

Amostras de ar, superfícies de prateleiras e de queijos foram obtidas, em três momentos diferentes, no interior de câmara de maturação de queijo tipo parmesão. As amostras foram tomadas em doze pontos (ar) e dez pontos (prateleiras e superfícies) previamente definidos e fixados. Todas as coletas, a cada tempo, foram realizadas simultaneamente e no mesmo local a fim de garantir os resultados. A primeira coleta foi feita antes do início da ozonização e as outras duas com intervalo de vinte dias entre as coletas. O intervalo entre coletas foi definido aleatoria- mente, sendo que queijos e prateleiras eram escovados a cada dois dias, e os queijos virados.

Para a amostragem do ar, utilizou-se a técnica de sedimentação espontânea, onde placas de Petri contendo ágar batata dextrose (PDA) acidificado a pH 3,6 foram expostas ao ambiente da câmara de maturação por 15 minutos. As placas de Petri foram incubadas a $25^{\circ} \mathrm{C}$, por 3-5 dias para posterior contagem.

Para amostragem da superfície dos queijos e das prateleiras, utilizaram-se suabes e régua para coleta de $100 \mathrm{~cm}^{2}$ [1]. Após a coleta nas superfícies, o suabe foi inoculado em $10 \mathrm{~mL}$ de água peptonada, de onde foram retiradas alíquotas para diluição $10^{-1}$ que foram inoculadas em ágar PDA e incubadas. A cada tempo de coleta nas superfícies, foi obtida amostragem de área adjacente à coletada anteriormente a fim de evitar a diminuição da carga pelo arraste do suabe. Os pontos de coleta estão descritos na Figura 1.

A superfície dos queijos e prateleiras foi regularmente higienizada por sistema mecânico que realiza a viragem dos queijos periodicamente, bem como escovação de sua superfície e raspagem das prateleiras de madeira onde os mesmos são depositados.

A aplicação de ozônio foi realizada através de quatro geradores, cada um com capacidade de gerar $30 \mathrm{mgO}_{3} / \mathrm{h}$, instalados nas saídas de ar do sistema da ventilação da câmara de maturação com volume total de $250 \mathrm{~m}^{3}$. A liberação de $0,48 \mathrm{mg}$ de $\mathrm{O}_{3} / \mathrm{m}^{3}$ ocorreu de forma intermitente, sendo que os mesmos permaneceram ligados $70 \%$ do tempo total. A temperatura da câmara foi mantida constante, a $15^{\circ} \mathrm{C}$.

Os dados obtidos foram transformados pela aplicação de log natural (base 10) para obter uma distribuição normal de dados. A diferença significativa entre as médias foi calculada através da análise de variância e o teste de Tukey, utilizando-se o programa GraphPad Prism 4.0 e aplicando um nível de significância de $5 \%(\alpha=0,05)$ [7].

\section{RESULTADOS}

Foram coletadas 96 amostras, sendo 36 do ar ambiental, 30 das superfícies de prateleiras e 30 das superfícies dos queijos, nos diferentes tempos.

Na Tabela 1 estão apresentados os resultados das contagens de fungos em suspensão no ambiente, ao longo do tempo. Pode-se observar que a contagem fúngica decresce ao longo do tempo.

Observou-se diminuição média de dois ciclos logarítmicos na contaminação fúngica ambiental. 


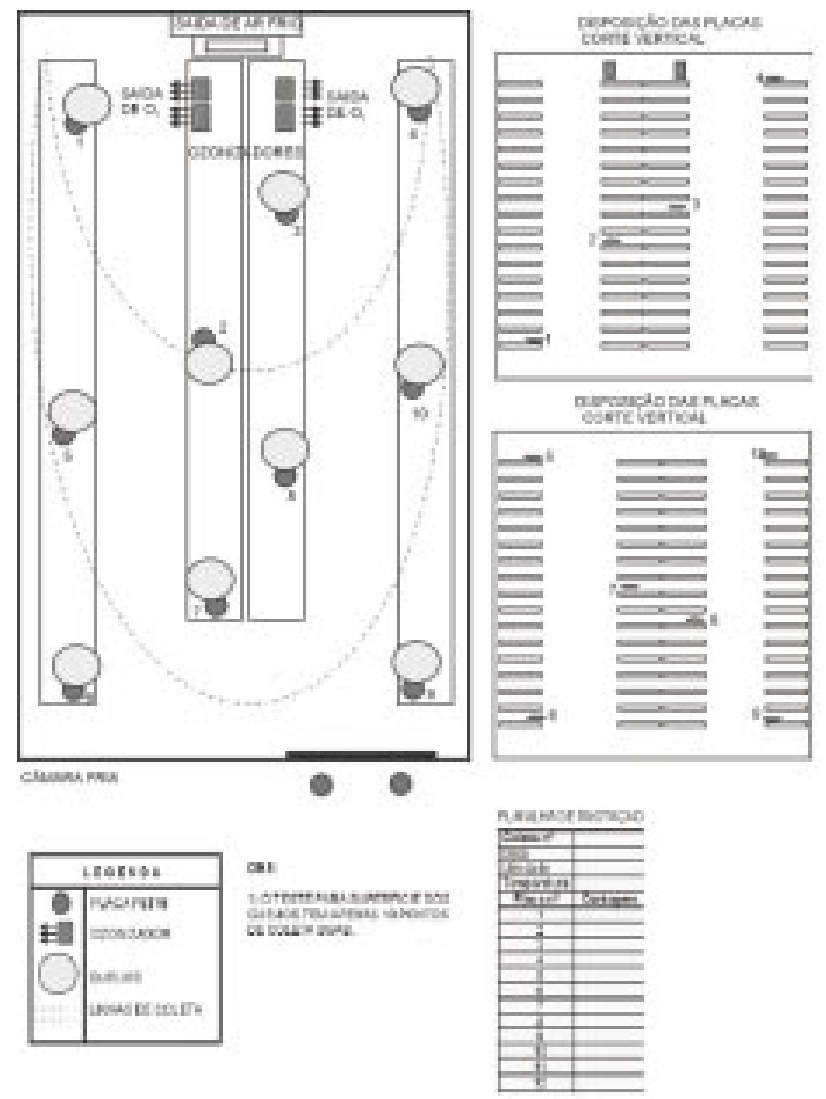

Figura 1. Localização dos pontos de coleta de ar, superfície de queijos e prateleiras no interior da câmara de maturação onde foi adicionado ozônio.
Mesmo nos pontos de coleta 11 e 12, que se localizavam fora da câmara, observa-se a diminuição da contaminação ambiental.

Na Tabela 2 estão expostos os resultados das contagens fúngicas de superfície de prateleiras. Nesta situação pode-se observar, também, o decréscimo da viabilidade dos fungos ao longo do tempo. A contaminação superficial das prateleiras apresentou uma diminuição de carga fúngica média de um ciclo logarítmico ao longo do período de tempo analisado.

A Tabela 3 apresenta os resultados de contagem fúngica superficial nos queijos. A aplicação de ozônio, neste caso, também se mostrou eficiente na redução de carga fúngica.

No presente estudo, a desinfecção por ozonização em sala fechada foi efetiva no controle de fungos. Observou-se diminuição de um ciclo logarítmico das contagens fúngicas em superfícies das prateleiras e de 0,8 ciclo na superfície dos queijos.

Não ocorreram alterações sensoriais nos queijos analisados durante o período do experimento.

\section{DISCUSSÃO}

O trânsito de pessoas e produtos é potencial disseminador de fungos para o exterior da câmara e

\begin{tabular}{|c|c|c|c|}
\hline \multirow{2}{*}{$\begin{array}{c}\text { Ponto de } \\
\text { amostragem }\end{array}$} & \multicolumn{3}{|c|}{ Contagem de fungos $\left(\log _{10}\right.$ UFC) } \\
\hline & T zero & T 20 dias & T 40 dias \\
\hline 1 & 3,42 & 3,47 & 1,48 \\
\hline 2 & 3,68 & 3,20 & 1,43 \\
\hline 3 & 3,45 & 3,14 & 1,72 \\
\hline 4 & 3,68 & 3,21 & 1,62 \\
\hline 5 & 3,56 & 3,03 & 1,54 \\
\hline 6 & 3,48 & 3,52 & 1,59 \\
\hline 7 & 3,55 & 3,33 & 1,45 \\
\hline 8 & 3,70 & 3,30 & 1,38 \\
\hline 9 & 3,50 & 3,33 & 1,30 \\
\hline 10 & 3,79 & 3,37 & 1,72 \\
\hline 11 & 3,71 & 3,07 & 1,59 \\
\hline 12 & 3,71 & 3,16 & 1,54 \\
\hline Média (D.padrão) & $3,60^{\mathrm{a}}( \pm 0,123)$ & $3,26^{b}( \pm 0,152)$ & $1,53^{\mathrm{c}}( \pm 0,129)$ \\
\hline
\end{tabular}




\begin{tabular}{|c|c|c|c|}
\hline \multirow{2}{*}{$\begin{array}{l}\text { Ponto de } \\
\text { amostragem }\end{array}$} & \multicolumn{3}{|c|}{ Contagem de fungos $\left(\log _{10}\right.$ UFC/100 $\left.\mathrm{cm}^{2}\right)$} \\
\hline & T zero & T 20 dias & T 40 dias \\
\hline 1 & 3,68 & 3,06 & 2,43 \\
\hline 2 & 3,68 & 3,18 & 2,15 \\
\hline 3 & 3,68 & 3,23 & 2,32 \\
\hline 4 & 3,82 & 3,19 & 3,90 \\
\hline 5 & 3,62 & 2,99 & 3,04 \\
\hline 6 & 3,71 & 3,00 & 2,59 \\
\hline 7 & 3,65 & 3,00 & 2,78 \\
\hline 8 & 3,72 & 3,20 & 2,84 \\
\hline 9 & 3,81 & 3,18 & 3,03 \\
\hline 10 & 3,60 & 3,21 & 2,58 \\
\hline Média (D.padrão) & $3,71^{\mathrm{aA}}( \pm 0,072)$ & $3,12^{\mathrm{bA}}( \pm 0,099)$ & $2,78^{\mathrm{bB}}( \pm 0,494)$ \\
\hline
\end{tabular}

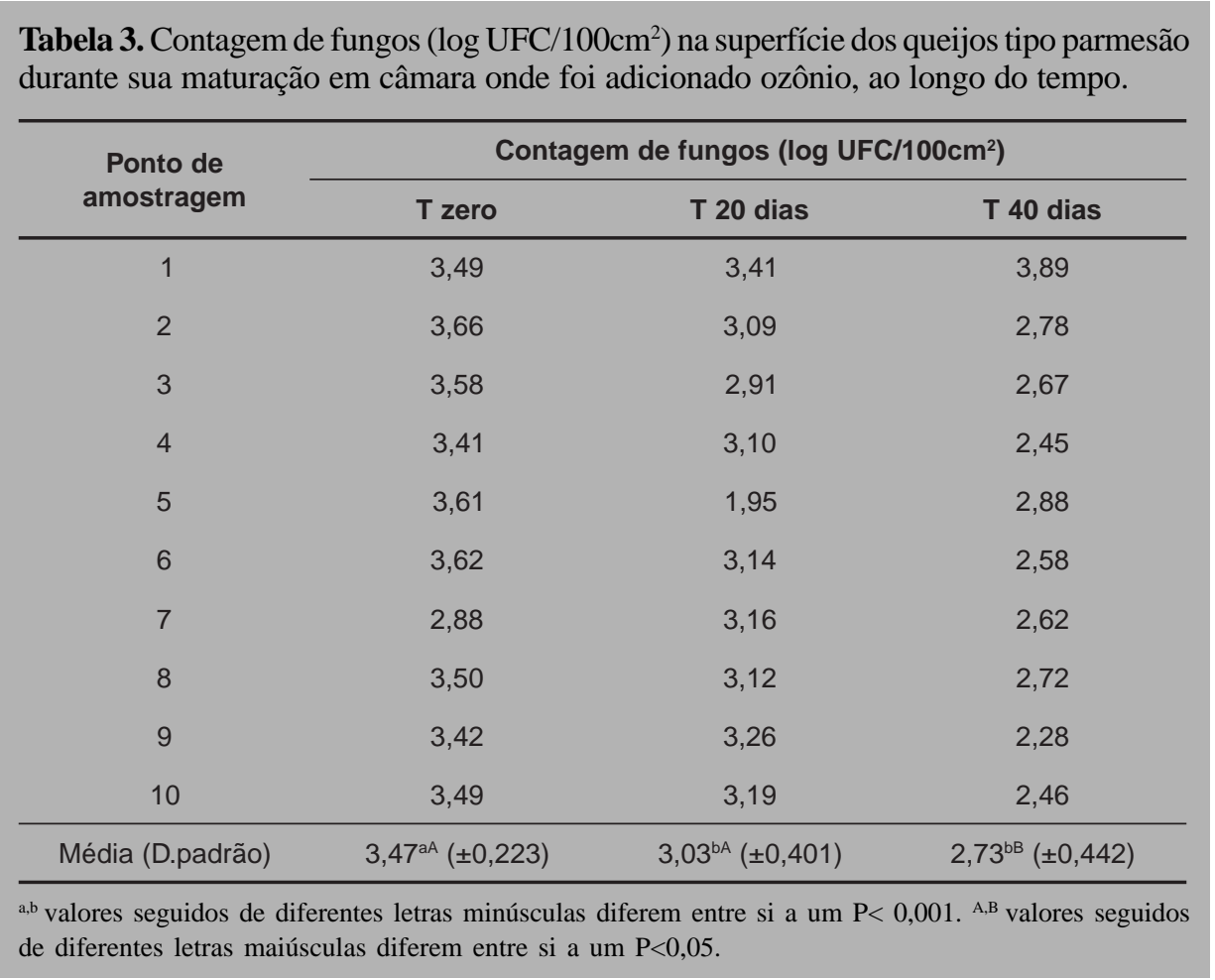

a cada abertura de porta há contaminação cruzada. Com a diminuição da carga fúngica interna, foi possível observar que o ambiente, como um todo, melhora sua qualidade, evitando-se, assim a recontaminação do interior da câmara. É possível constatar, também que há uma diminuição progressiva com ten- dência à eliminação da presença de fungos no ambiente. A diminuição de carga fúngica ambiental já foi comprovada em ambientes semelhantes ao em estudo [11] e hospitalar [4].

Não foi observada diminuição da contagem superficial de fungos com a aplicação de ozônio em 
superfícies de câmaras de maturação de queijos, em estudos anteriores [11], quando as superfícies não eram higienizadas. Entretanto, em ambiente hospitalar foi possível identificar a redução em até dos ciclos logarítmicos em superfícies de trabalho de ambientes hospitalares, cuja higienização era realizada [4].

Os queijos monitorados indicam que, mesmo na superfície deste alimento, é possível provocar redução dos fungos, impedindo a produção de exoenzimas capazes de provocar alterações sensoriais $[2,6,10] \mathrm{e}$ mesmo a produção de toxinas [14]. Além disto, o controle destes fungos na superfícies dos queijos e a melhoria da qualidade ambiental vão refletir em uma maior vida-de-prateleira do produto, o que está associado ao uso do ozônio [9].
As dosagens de ozônio utilizadas não foram capazes de provocar danos sensoriais no produto, $o$ que era esperado, uam vez que, mesmo dosagens de $10 \mathrm{mg} / \mathrm{m}^{3}$ não provocam alterações desta ordem [12].

\section{CONCLUSÕES}

A proliferação de fungos ambientais pode ser diminuída com a aplicação de ozônio no ambiente de maturação de queijos. Devem ser realizados estudos de dosagem e tempo de aplicação, a fim de garantir a ausência de efeitos deletérios nos produtos armazenados. Esta poderá ser uma opção na desinfecção de ambientes de processo e armazenagem de alimentos. O uso de ozônio no ambiente não elimina a necessidade de realizar a limpeza periódica das superfícies em contato com o alimento.

\section{REFERÊNCIAS}

1 APHA - American Public Health Association. 2001. Compendium of methods for the microbiological examination of foods. 4th edn. Washington: APHA, 702p.

2 Filtenborg O., Frisvad J. C. \& Thrane U. 1996. Moulds in food spoilage. International Journal of Food Microbiology. 33: 85-102.

3 Gibson C.A., Elliott J.A. \& Beckett D.C. 1960. Ozone for controlling mold on cheddar cheese. Canadian Dairy and Ice Cream Journal. 14: 24-28.

4 Klánovoa K. \& Lajcíková A. 2006. Use of ozone to reduce bacteria and moulds in the air and on surfaces. Indoor and Built Environment. 15: 81-84.

5 Lund F., Filtenborg O. \& Frisvad J.C. 1995. Associated mycoflora of cheese. Food Microbiology. 12: 173-180.

6 Northold M.D., Van Egmond H.P., Soentoro P. \& Deijll E. 1980. Fungal growth and the presence of sterigmatocystin in hard cheese. Journal of Association Official Analitical Chemistry. 63: 115-119.

7 Pagano M. \& Gauvreau K. 2000. Princípios de Bioestatística. 2.ed. São Paulo: Thompson, 506p.

8 Prata A.F.G., Kraemer F.B., Florido P.S.S., Sgarbi D.B.G. \& Stussi J.S.P. 2001. Fungos toxigênicos e proteolíticos isolados de queijo tipo parmesão ralado e embalado, comercializado em Niterói, RJ. Higiene Alimentar. 15: 49-52.

9 Rice R.G., Far Quhar J.W. \& Bollyky L.J. 1982. Review of the applications of ozone for increasing storage time of perishable foods. Ozone: Science and Engineering. 4: 147-163.

10 Sensidoni A., Rondinini G., Peressini D., Maifreni M. \& Bortolomeazzi R. 1994. Presence of an off-flavour associated with the use of sorbates in cheese and margarine. Italian Journal of Food Science. 6: 237-242.

11 Serra R., Abrunhosa L., Kozakiewicz Z., Venâncio A. \& Lima N. 2003. Use of ozone to reduce molds in a cheese ripening room. Journal of Food Protection. 66: 2355-2358.

12 Shiler G.G., Eliseeva N.N. \& Chebotarev L.N. 1978. Use of ozone and ultra-violet radiation for the inactivation of mould spores. In: Annals of XX International Dairy Congress (Paris,France). p.667.

13 Taniwaki M.H. \& Van Dender A.G.F. 1992. Occurrence of toxigenic molds in Brazilian cheese. Journal Food Protection. 55: $187-191$.

14 Tantaqui-Elaraki A. \& Khabbazi N. 1984. Contamination éventuelle des fromages par les mycotoxines: une revue. $L e$ Lait. 64: 46-71.

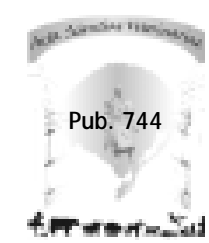

